\title{
Flood Damage Area Detection Method by Means of Coherency Derived from Interferometric SAR Analysis with Sentinel-A SAR
}

\author{
Kohei Arai ${ }^{1}$, Hiroshi Okumura ${ }^{2}$, Shogo Kajiki ${ }^{3}$ \\ Science and Engineering Faculty \\ Saga University, Saga City \\ Japan
}

\begin{abstract}
Flood damage area detection method by means of coherency derived from interferometric SAR analysis with Sentinel-A SAR is proposed. One of the key issues for flooding area detection is to estimate it as soon as possible. The flooding area due to heavy rain, typhoon, severe storm, however, is usually covered with clouds. Therefore, it is not easy to detect with optical imagers onboard remote sensing satellite. On the other hand, Synthetic Aperture Radar: SAR onboard remote sensing satellites allows to observe the flooding area even if it is cloudy and rainy weather conditions. Usually, flooding area shows relatively small back scattering cross section due to the fact that return signal from the water surface is quite small because of dielectric loss. It, however, is not clear enough of the flooding area detected by using return signal of SAR data from the water surface. The proposed method uses coherency derived from interferometric SAR analysis. Through experiment, it is found that the proposed method is useful to detect the flooding area clearly.
\end{abstract}

Keywords-Flooding area detection; Synthetic Aperture Radar: SAR; interferometric SAR analysis; coherency; back scattering cross section; remote sensing satellite

\section{INTRODUCTION}

One of the key issues for flooding area detection is to estimate it as soon as possible. The flooding area due to heavy rain, typhoon, severe storm, however, is usually covered with clouds. Therefore, it is not easy to detect with optical imagers onboard remote sensing satellite. On the other hand, Synthetic Aperture Radar: SAR onboard remote sensing satellites allows to observe the flooding area even if it is cloudy and rainy weather conditions.

Flooding and oil spill disaster relief using Sentinel of remote sensing satellite data is conducted [1]. SAR image classification based on Maximum Likelihood Decision rule with texture features taking into account a fitness to the probability density function is proposed [2]. On the other hand, a new method for SAR speckle noise reduction (Chi-Square Test Filter) is proposed and validated with actual satellite based SAR data [3].

Decomposition of SAR polarization signatures by means of eigen-space representation is proposed [4]. Meanwhile, polarimetric SAR image classification with maximum curvature of the trajectory in eigen space domain on the polarization signature is attempted [5]. On the other hand,
Wavelet Multi-Resolution Analysis: MRA and its application to polarimetric SAR classification is proposed and validated [6].

Sentinel 1A SAR data analysis for disaster mitigation in Kyushu, Japan is conducted [7]. On the other hand, polarimetric SAR image classification with maximum curvature of the trajectory in eigen space domain on the polarization signature is proposed [8].

Polarimetric SAR image classification with high frequency component derived from wavelet multi resolution analysis: MRA is proposed and validated [9]. Also, comparative study of polarimetric SAR classification methods including proposed method with maximum curvature of trajectory of backscattering cross section in ellipticity and orientation angle space is conducted [10].

Characteristics of heavy rainfall and flood disaster in central southern part of Oita prefecture by Typhoon No.18 "Typhoon Talim" in 2017), flooding areas in the Tsukumi city due to Typhoon No.18 are investigated [11]. Sentinel 1A SAR data analysis for disaster mitigation in Kyushu is conducted and reported [12], Also, Wavelet Multi-Resolution Analysis: MRA and its application to polarimetric SAR classification is proposed [13].

Usually, flooding area shows relatively small back scattering cross section due to the fact that return signal from the water surface is quite small because of dielectric loss. It, however, is not clear enough of the flooding area detected by using return signal of SAR data from the water surface. The proposed method uses coherency ${ }^{1}$ derived from interferometric SAR analysis. Through experiment, it is found that the proposed method is useful to detect the flooding area clearly.

The following section describes research background, in particular, flooding damage due to typhoon No.18, which hit Japanese island. Then some experimental results, in particular, a comparison of flooding area observed on the ground and detected flooding area using Sentinel-1 SAR data through interferometric SAR analysis (coherency). After that conclusion is described with some discussions.

\footnotetext{
${ }^{1}$ https://en.wikipedia.org/wiki/Coherence_(signal_processing)
} 


\section{RESEARCH BACKGROUND}

\section{A. Typhoon No. 18 in 2017}

Typhoon No. 18, which occurred in the Mariana Islands on September 9 in 2017, traveled northwest in the south of Japan, and moved northward near Miyakojima on the 13th with a very strong force. The typhoon turned to the east in the East China Sea on the 15th in September and landed near Minamikyushu City in Kagoshima Prefecture at around 11:30 on the $17^{\text {th }}$ in September. After that, the typhoon moved north along the Japanese archipelago along with the storm area, relanded in Kochi prefecture, Hyogo prefecture, and Hokkaido, and became a temperate cyclone in Sakhalin at 21:00 on the $18^{\text {th }}$ in September.

Due to the effects of typhoons and active fronts, heavy rains and storms occurred mainly in the Nansei Islands, western Japan, and Hokkaido. In addition, due to the typhoon, the storm surged mainly in the Nansei Islands and western Japan, and the storm surge occurred mainly in western Japan because it coincided with the tide.

Due to these effects, river floods, flood damage, and sediment disasters occurred mainly in Oita prefecture and western Japan. In addition, there were damages to lifelines such as water outages and telephone interruptions in various places, as well as traffic disruptions such as suspension of railroads and cancellation of aircraft and ships. Fig. 1 shows the trajectory of the typhoon No.18, Talim which hit Japanese island during on 17th of September and $18^{\text {th }}$ of September 2017.. Also, Fig. 2 shows Geo-stational Meteorological Satellite image of Typhoon No.18 over Kyushu, Japan acquired on 17 September 2017.

\section{B. Intensive Study Areas}

Fig. 3 shows the intensive study area of Usuki and Tsukumi areas of Kyushu, in Japan of which flood damaged areas due to Typhoon No.18 during 17 and 18 September 2017.

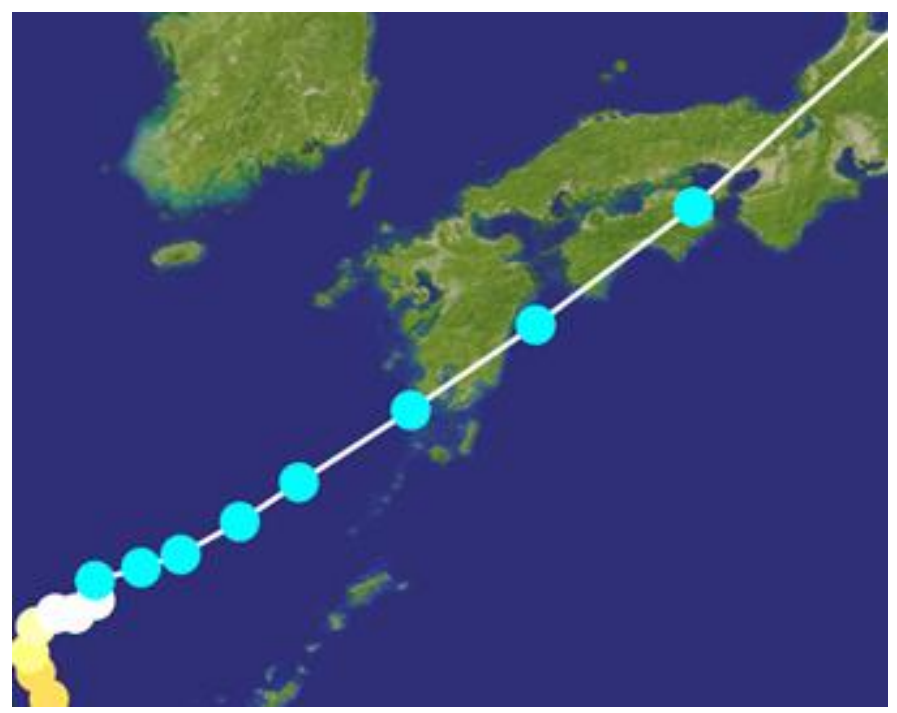

Fig. 1. Trajectory of the Typhoon No.18.

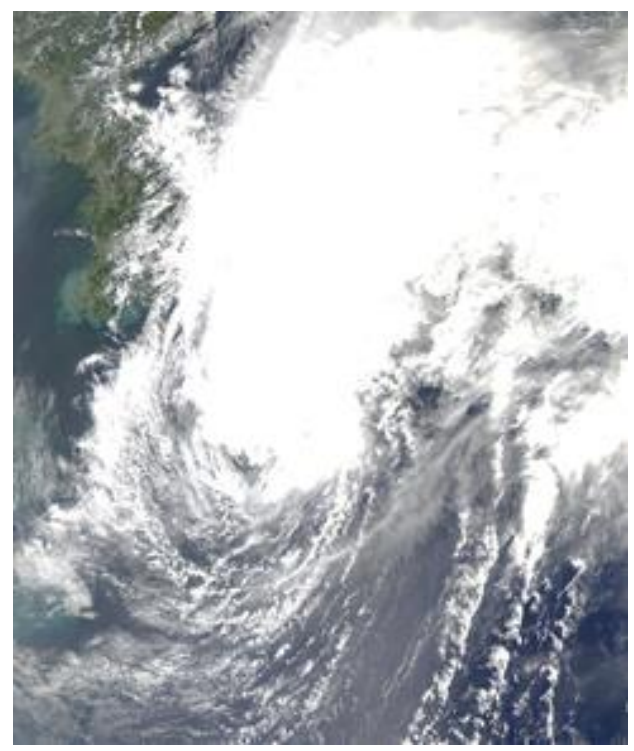

Fig. 2. Geo-Stational Meteorological Satellite image of Typhoon No.18 over Kyushu, Japan Acquired on 17 September 2017.

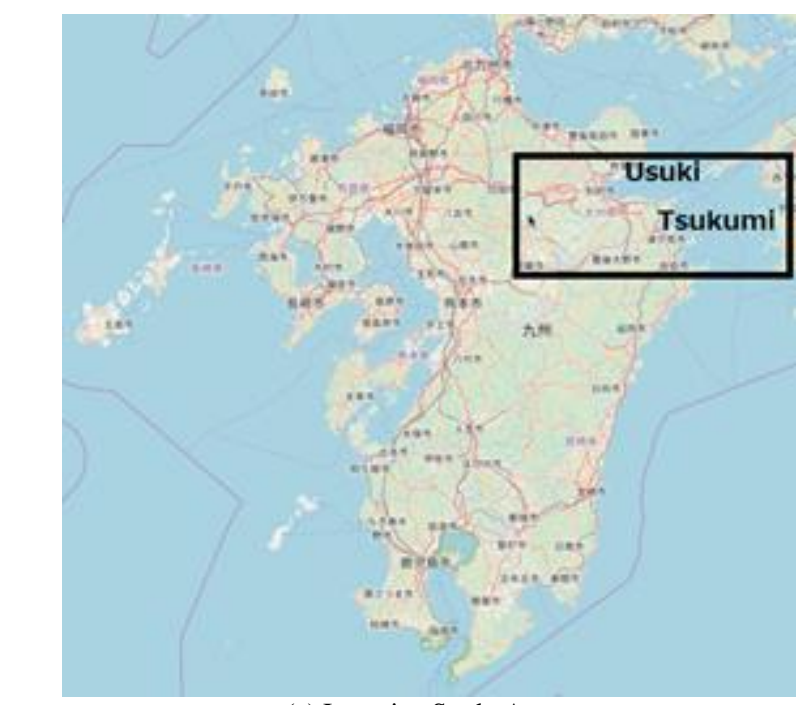

(a) Intensive Study Areas.

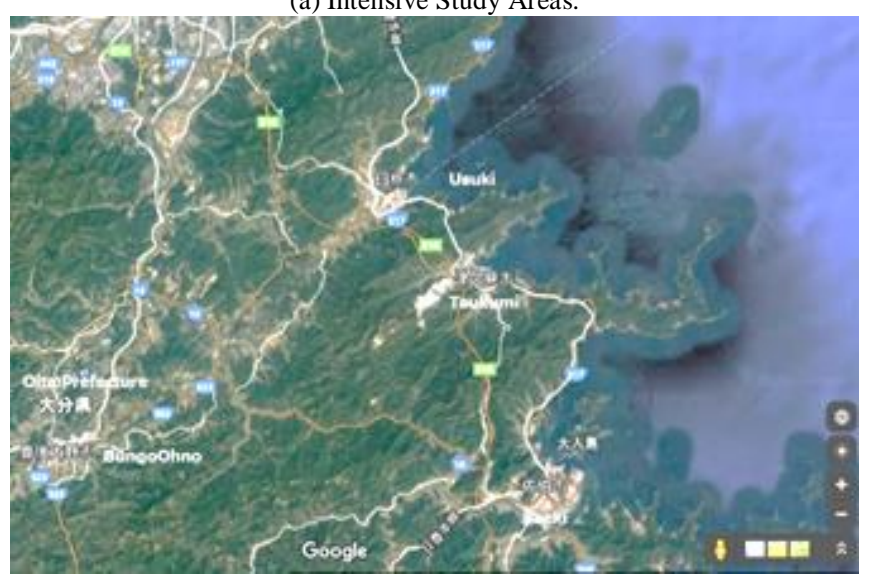

(b) Enlarged Google Map Image of the Intensive Study Areas.

Fig. 3. Intensive Study Area of Usuki and Tsukumi Areas of Kyushu, in Japan of which Flood Damaged Areas due to Typhoon No.18 during 17 and 18 September 2017. 


\section{Rainfall Rate and Wind Direction as well as Wind Speed}

From Journal of Japanese Society on Natural Disaster Science, 36 -4 381 -397 (2018) by Haruhiko YAMAMOTO, Toshiaki YAMASAKI, Kyoko SAKAMOTO and Nao YAMASHITA, Characteristics of Heavy Rainfall and Flood Disaster in Central Southern part of Oita Prefecture by Typhoon No.18 "Typhoon Talim" in 2017 [11], rainfall rate and ground wind direction and wind speed are investigated. These are shown in Fig. 4.

Prof. Dr. Yamamoto conducted ground survey of the flooding situation in the Tsukumi city in Oita prefecture of Japan. The flooding areas in the city is shown in Fig. 5.

D. Damage Due to Typhoon No.18 Which Hit Kyushu on $17^{\text {th }}$ of September 2017

Major damages due to Typhoon No.18 are as follows,

1) 5 dead, 59 injured.

2) Completely destroyed 3 houses, 11 partially destroyed, 531 partially destroyed.

3) 1,970 buildings on the floor, 4,653 buildings under the floor, etc.

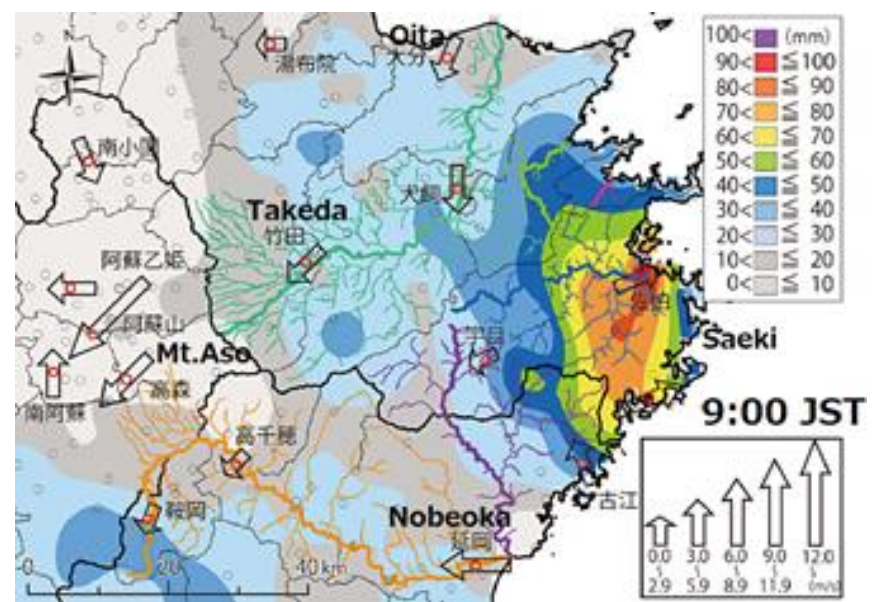

(a) Wind Direction and Wind Speed as well as Rainfall Rate Observed at 9:00 Japanese Standard Time: JST on 17th September 2017.

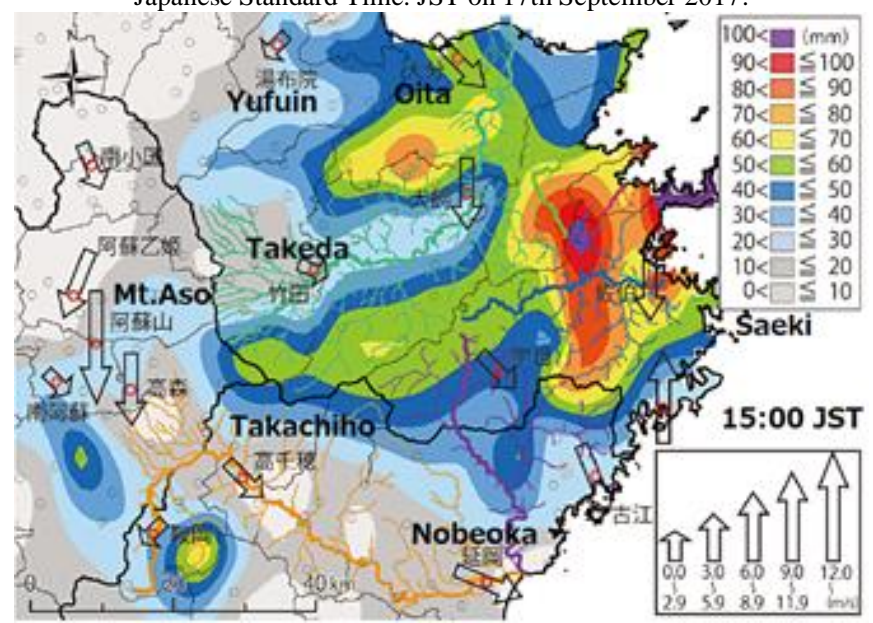

(b) Wind Direction and Wind Speed as well as Rainfall Rate Observed at 15:00 Japanese Standard Time: JST on 17th September 2017.

Fig. 4. Wind Direction and Wind Speed as well as Rainfall Rate Observed at 9:00 and 15:00 Japanese Standard Time: JST on 17 ${ }^{\text {th }}$ September 2017.

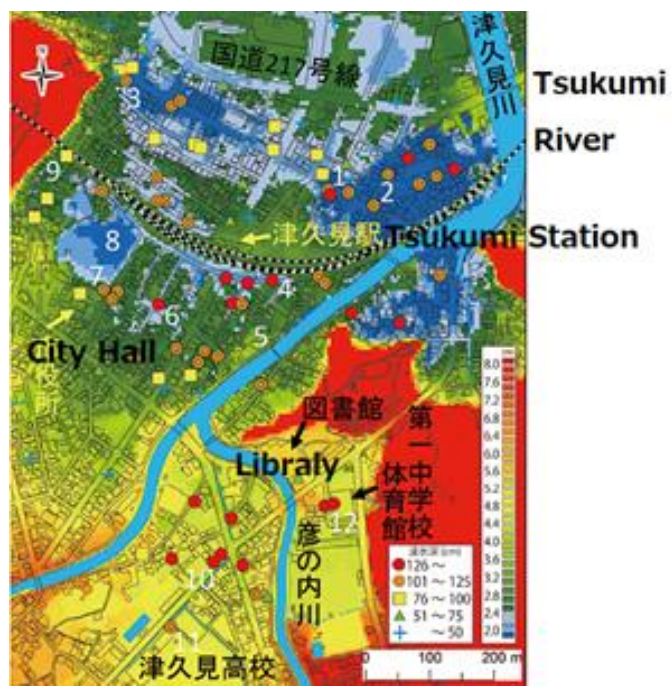

Fig. 5. Flooding Areas in the Tsukumi City Due to Typhoon No.18 (From Journal of Japanese Society on Natural Disaster Science, 36 -4 381 -397 (2018) by Haruhiko YAMAMOTO, Toshiaki YAMASAKI, Kyoko SAKAMOTO and Nao YAMASHITA, Characteristics of Heavy Rainfall and Flood Disaster in Central Southern part of Oita Prefecture by Typhoon No.18 “Typhoon Talim" in 2017).

In Oita prefecture, many rivers from central Oita prefecture to southern Oita prefecture flooded on the 17th. In Usuki City, the city was flooded, and the Governor of Oita issued a disaster dispatch request to the 41st Ordinary General of the Ground Self-Defense Forces in charge of flood control (disaster dispatch request was made at 13:00 on the 18th of the following day). In Tsukumi City, the Tsukumi River and Tokuura River flooded and flooded a wide area, including the Tsukumi City Hall. In addition, floods also occurred in the Ono River in Oita City and Bungo Ono City, the Isaki River in the Bansaku River System in Saiki City, and also in the Fengaru River in Usuki City and the Monzen River in Saiki City.

In Oita prefecture, river water is flooding everywhere. In Tsukumi City, the river flowing through the city overflowed and a wide area was flooded. After 3:00 pm on September 17, water flowed into the 1 st floor of the city hall, temporarily using the height of the ankle, and most of the surrounding area was flooded with water, and some cars floated on the water in the parking lot. In Bungo-Ono City, around $4 \mathrm{pm}$ on September 17, part of the Ono River in the shallows of Mie Town overflowed with water, and three houses along the river were flooded under the floor. Also, in Beppu City, Oita Prefecture, around $4 \mathrm{pm}$ on the $17^{\text {th }}$ September, earth and sand collapsed on the back mountain of the house. The back mountain collapsed over a height of about 5 meters and a width of about 5 meters, and the window glass on the first floor of the house was broken, but there were no injuries. At the Nishinomiya Shrine in Takeda City, Oita Prefecture, it was discovered that a stone wall 4 meters high collapsed over a width of 4 meters.

The collapsed stone wall is said to have collapsed to the site of the next house, but there is no damage to people or buildings. "In Tsukumi City, Oita Prefecture, where it seems to have been raining about $110 \mathrm{~mm}$ per hour, it seems that the 
river flowing through the city overflowed and a large area was flooded, but police and fire departments were all over the road. He said that he could not patrol as expected after flooding, and that he did not understand the full extent of the damage.

According to Tsukumi City, the residents flooded the Tsukumi River and Tokuura River, which flowed in the city from about 2:30 pm, with messages saying that the underfloor of the house was flooded. After 3:00 pm, the water flowed to the first floor of the city hall, and the height of the ankle was used for a while.

Depending on the city, water gradually begins to drain, and as of 6:00 pm, the flood in the city hall has disappeared, and there are some roads around the city where water can begin to drain. However, according to police and fire departments, the roads are still flooded everywhere in the city, so the patrol to confirm the damage does not proceed as expected and the whole situation is not grasped.

\section{PROPOSED METHOD}

\section{A. Interferometric SAR}

The signals received by antennas 1 and 2 are processed to generate two sets of complex images, and the product $\mathrm{A}_{1} \mathrm{~A}^{*}{ }_{2}$ $=\left|\mathrm{A}_{0}\right|^{2}$ of the complex amplitude $\mathrm{A}_{1}$ of image 1 and the complex conjugate $\mathrm{A}^{*}{ }_{2}$ of image 2 called interferogram.

$\exp (\mathrm{i} \varphi)=\left|\mathrm{A}_{0}\right|^{2}(\cos (\varphi)+\mathrm{i} \sin (\varphi))$

where, $\varphi=\varphi_{1}-\varphi_{2}=2 \mathrm{k}\left(\mathrm{R}_{1}-\mathrm{R}_{2}\right)$ is the phase difference, $\mathrm{k}=$ $2 \pi / \lambda$ is the wave number, and $A_{0}$ is a constant including RCS and is constant throughout both images. The phase of the interferogram is as follows,

$\psi=\arctan \left(\operatorname{imag} .\left(\mathrm{A}_{1} \mathrm{~A}^{*}{ }_{2}\right) / \operatorname{real}\left(\mathrm{A}_{1} \mathrm{~A}{ }^{*}{ }_{2}\right)\right)=\varphi+\mathrm{j} 2 \pi$ :

$\mathrm{j}=0, \pm 1, \pm 2, \pm 3, \ldots$

Extracted phase $\psi$ is folded between $(0,2 \pi]$ every $2 \pi$, and the absolute phase (absolute or unwrapped phase) is calculated by removing the ambiguity of $2 \pi$ from the wrapped phase. This processing technique is called phase unwrapping or phase recovery, and many methods have been proposed. Relationship between phase of interferogram and ground surface height $\varphi=(4 \pi / \lambda)$ BCT $\sin \left(\theta_{\mathrm{i}}-\gamma \mathrm{CT}\right)$. The ground surface altitude is obtained, but at present, it is difficult to obtain highly accurate orbit information from platform information. Therefore, the change in the ground surface height is as follows,

$$
\Delta \mathrm{H}=\lambda \mathrm{R}_{1} \sin \theta_{\mathrm{i}} 4 \pi \mathrm{BCT} \cos \left(\theta_{\mathrm{i}}-\gamma \mathrm{CT}\right) \Delta \varphi
$$

And is extracted from the difference between the two points on the image. Here, $\Delta \mathrm{H}$ and $\Delta \varphi$ are the change in the ground surface altitude and the change in the interferogram phase at two points, respectively. In actual processing, there is speckle-specific noise in the coherent imaging system, so arithmetic processing is performed as a set average interferogram phase with some noise reduction. The coherence image showing the correlation of complex images is defined by the following equation:

$\Gamma_{12}=\left|\mathrm{A}_{1} \mathrm{~A} *{ }_{2}\right| / \mathrm{I}_{1} \mathrm{I}_{2}$ where, $I_{j} ;(j=1,2)$ represents the set average of the intensities $\mathrm{I}_{\mathrm{j}}$.

The coherence of the interferogram generated by the interferometric SAR and the differential interferometric SAR described later depends on the degree of correlation of the backscatter field. In the repeat path InSAR, when the scatterer changes between paths, the degree of correlation of the backscattering field decreases and the coherence of the interferogram also decreases. In forests where the volume scattering is the main, the coherence may decrease due to the change of the reflection path due to a slight difference in the incident angle. Utilizing this phenomenon, research is being conducted to measure the characteristics of spatterers and spatiotemporal changes from coherence. For example, if $\lambda=$ $23.5 \mathrm{~cm}, \mathrm{R}_{1}=750 \mathrm{~km}, \gamma \mathrm{CT}=0, \theta_{\mathrm{i}}=40^{\circ}$, and BCT $=1 \mathrm{~km}$, one cycle of interference fringes corresponds to an altitude difference of about $74 \mathrm{~m}$. The longer the orbital interval, the shorter the interval of interference fringes and the higher the measurement accuracy. In order to generate a good quality interferogram, there is a trade-off between the two.

For satellite C-band SAR such as ENVISAT-ASAR and RADARSAT-1, the available orbital intervals are around $0.5 \mathrm{~km}$ and the JERS-1 L-band SAR., it is about $1 \mathrm{~km}$. Regarding the accuracy of the InSAR-DEM, the DEM by airborne In-SAR has an error of about 2 to $5 \mathrm{~m}$ compared with the DEM obtained from optical stereo vision, but the error by using multi-wavelength and multi-polarization InSAR It has been reported that the result can be reduced by about $30 \%$. As the slope of the ground surface increases, layover, foreshortening, and shadow effects increase and coherence decreases, so the measurement error generally increases.

It is difficult for satellite-borne InSAR to completely eliminate interference fringes due to orbital intervals due to the uncertainty of orbit information and the curved surface of the ground surface. This is due to coherence degradation due to ground surface inclination and signal delay due to atmospheric water vapor Due to some errors, the measurement error from a single interferogram is often several meters to several tens of meters. However, satellite orbit information is becoming more accurate, and it is possible to reduce the measurement accuracy below the resolution range by using multiple interferograms with high coherence generated from data under different orbit intervals and meteorological conditions.

\section{B. Proposed Method}

The definition of the coherence for complex data is given by the following equation,

$\mu_{0}=<\left(x_{1}-<x_{1}>\right)\left(\left(x_{2}-<x_{2}>\right)^{*}>\left(\sigma_{x_{1}} \sigma_{x_{2}}\right)\right.$

where: \langle\rangle is the expectation operator $x_{1}, x_{2}$ are the pixels from the two images being correlated, image 1 and 2, respectively. $*$ denotes complex conjugate while $\sigma_{x i}$ is the square-root of the variance for the pixel from the i-th image.

The proposed method for flooding area detection is to use the coherency. Namely, coherency reflects correlation between two SAR imagery data, master and slave images. Therefore, correlation between two SAR imagery data, before 
and after the typhoon hit the intensive study areas supposed to be flooding areas.

The coherency between two SAR imagery data (before flooding and after flooding) indicates the difference of back scattering cross section of the land surface covered with water. Therefore, it is possible to detect flooding areas by using coherency which is expressed with the equation (5).

\section{EXPERIMENT}

\section{A. Data used}

The following Sentinel-1A SAR imagery data (see Fig. 6) which are acquired on September 7 in 2017 (just before the Typhoon No.18) and September 19 in 2017 (just after the Typhoon No.18) are used for the experiment.

Descending orbit (Descending path)

Observation wavelength: $\mathrm{C}$ band

Polarization: VV

Date of disaster (central day): September 16-17, 2017 (JP)

Data used for processing...

Two periods before the disaster

Time 1: August 26, 2017 (JP), preliminary orbit data

Period 2: September 7, 2017 (JP), preliminary orbit data

Two times between the days of disaster

Timing 1: September 7, 2017 (JP), preliminary orbit data

Period 2: September 19, 2017 (JP), preliminary orbit data
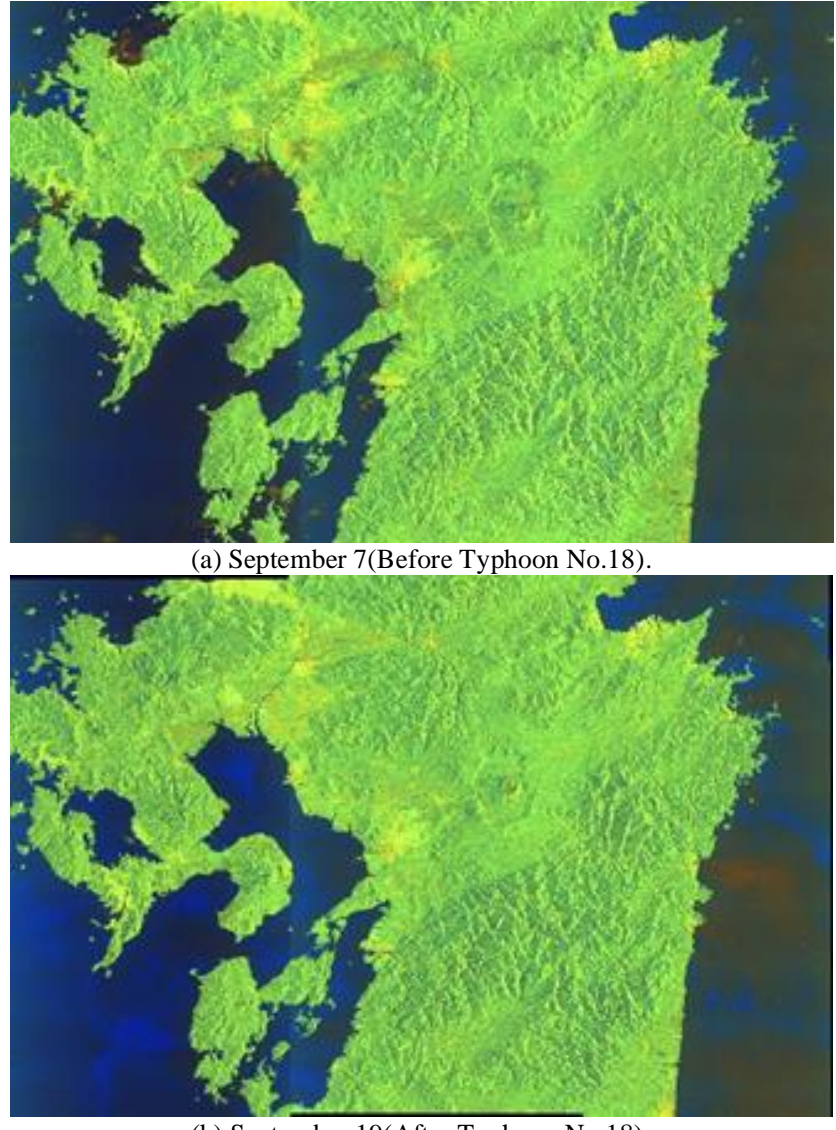

(b) September 19(After Typhoon No.18).

Fig. 6. Two Sentinel-1A SAR Imagery Data used.

\section{B. Coherence Image}

Using the aforementioned two Sentinel-1A SAR imagery data (before and after the typhoon No. 18), coherency defined as Eq. 5 is calculated. The resultant coherency image is shown in Fig. 7(a). Meanwhile, Fig. 7(b) shows the coherence image on Google Earth while Fig. 7(c) shows coherence image of the intensive study area and Fig. 7(d) shows the intensive study area on Google map.

\section{Major Result}

In comparison between the Fig. 7(c) (derived from the coherence image) and Fig. 5 (Truth data of flooding areas), it is confirmed coincidence between both. Namely, proposed method for flooding area detection using coherence image does works well.

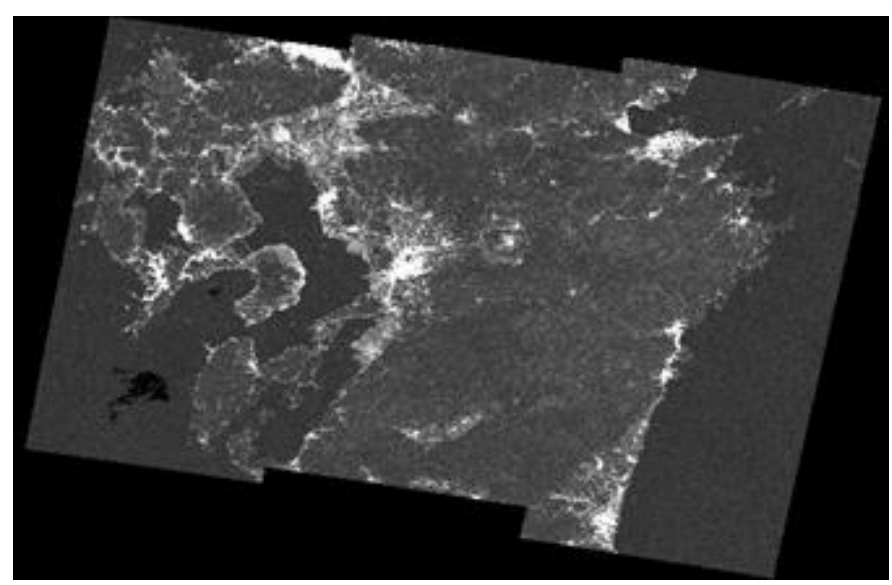

(a) Coherency Image.

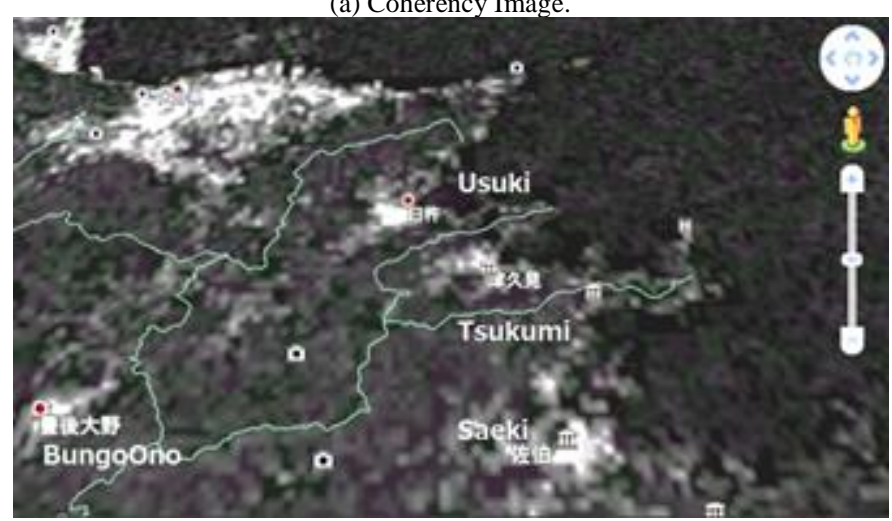

(b) Coherency Image on Google Earth.

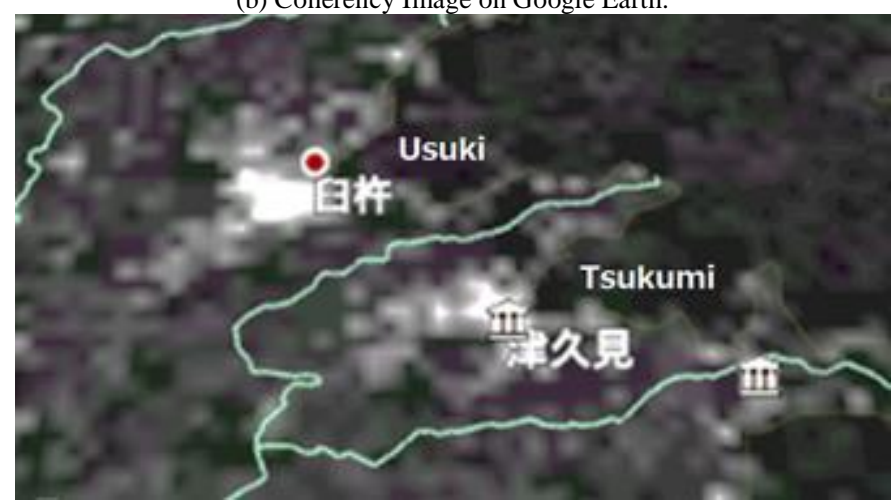

(c) Enlarged Coherency Image of the Intensive Study Area. 


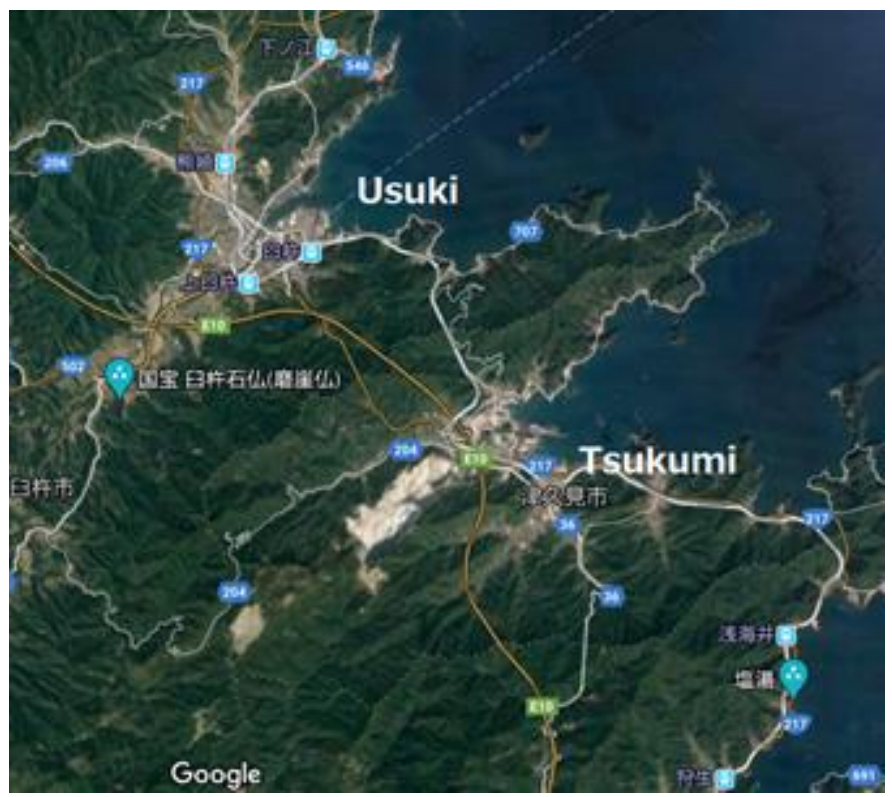

(d) Intensive Study Area on Google Map.

Fig. 7. Coherency Image of the Intensive Study Area.

\section{Elevation Changes between Two Periods, before and after} the Typhoon No.18

Using interferogram derived from two Sentinel-1A SAR imagery data (before and after the typhoon No.18), it is possible to create the elevation changes during the typhoon No.18. The resultant elevation change image is shown in Fig. 8 .

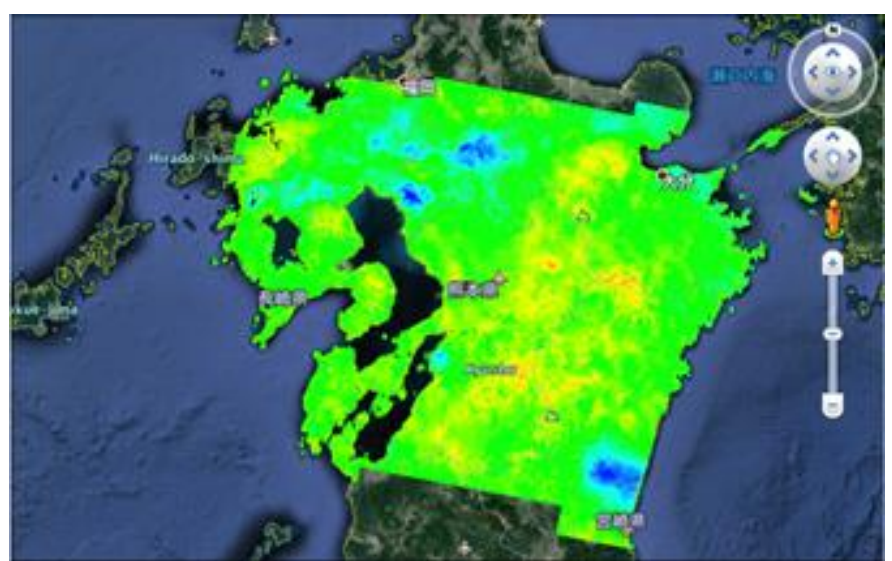

Fig. 8 Interferogram showing elevation changes between two time periods, before and after the Typhoon No.18

\section{CONCLUSION}

Flood damage area detection method by means of coherency derived from interferometric SAR analysis with Sentinel-A SAR is proposed. One of the key issues for flooding area detection is to estimate it as soon as possible. The flooding area due to heavy rain, typhoon, severe storm, however, is usually covered with clouds. Therefore, it is not easy to detect with optical imagers onboard remote sensing satellite. On the other hand, Synthetic Aperture Radar: SAR onboard remote sensing satellites allows to observe the flooding area even if it is cloudy and rainy weather conditions. Usually, flooding area shows relatively small back scattering cross section due to the fact that return signal from the water surface is quite small because of dielectric loss. It, however, is not clear enough of the flooding area detected by using return signal of SAR data from the water surface. The proposed method uses coherency derived from interferometric SAR analysis. Through experiment, it is found that the proposed method is useful to detect the flooding area clearly.

In comparison between the Fig. 7 (c) (derived from the coherence image) and Fig. 5 (Truth data of flooding areas), it is confirmed coincidence between both. Namely, proposed method for flooding area detection using coherence image does works well.

\section{FutURE RESEARCH WORKS}

Further research works are required for the conventional method using optical sensor data and interferogram. Also, classification methods have to be tried to detect flooding areas in remote sensing satellite imagery data.

\section{ACKNOWLEDGMENT}

The authors would like to thank Prof. Dr. Osamu Fukuda of Saga University for his valuable comments and suggestions.

\section{REFERENCES}

[1] Kohei Arai, Flooding and oil spill disaster relief using Sentinel of remote sensing satellite data, International Journal of Advanced Computer Science and Applications IJACSA, 10, 12, 290-297, 2019.

[2] Kohei Arai,K. and Y.Terayama, SAR image classification based on Maximum Likelihood Decision rule with texture features taking into account a fitness to the probability density function, Final Report of JERS-1/ERS-1 System Verification Program, J2, vol.II, pp.2-415 to 424, Munich, Mar., 1995.

[3] Hiroshi.Wakabayashi and Kohei Arai, A New Method for SAR Speckle Noise Reduction(Chi-Square Test Filter), Canadian journal of Remote Sensing, Vol.22, No.2, pp.190-197, June 1996.

[4] Kohei Arai Decomposition of SAR Polarization Signatures by Means of Eigen-Space Representation, Proc. of the Synthetic Aparture Radar Workshop '98, 1998.

[5] Kohei Arai and Wang June, Polarimetric SAR image classification with maximum curvature of the trajectory in eigen space domain on the polarization signature, Abstracts of the 35th Congress of the Committee on Space Research of the ICSU, A3.1-0061-04, (2004).

[6] Kohei Arai, Wavelet Multi-Resolution Analysus and Its Application to Polarizatic SAR Classification, Proceeding of the SAI Computing Conference 2016.

[7] Kohei Arai, Sentinel 1A SAR Data Analysis for Disaster Mitigation in Kyushu, Kyushu Brunch of the Japanese Society on Remote Sensing, Special Lecture for Young Engineers on Remote Sensing, Nagasaki University, 2018.

[8] Kohei Arai and J.Wang, Polarimetric SAR image classification with maximum curvature of the trajectory in eigen space domain on the polarization signature, Advances in Space Research, 39, 1, 149-154, 2007.

[9] Kohei Arai, Polarimetric SAR image classification with high frequency component derived from wavelet multi resolution analysis: MRA, International Journal of Advanced Computer Science and Applications, 2, 9, 37-42, 2011.

[10] Kohei Arai Comparative study of polarimetric SAR classification methods including proposed method with maximum curvature of trajectory of backscattering cross section in ellipticity and orientation angle space, International Journal of Research and Reviews on Computer Science, 2, 4, 1005-1009, 2011.

[11] Haruhiko YAMAMOTO, Toshiaki YAMASAKI, Kyoko SAKAMOTO and Nao YAMASHITA, Characteristics of Heavy Rainfall and Flood 
Disaster in Central Southern part of Oita Prefecture by Typhoon No.18 "Typhoon Talim" in 2017), Flooding areas in the Tsukumi city due to Typhoon No.18 (From Journal of Japanese Society on Natural Disaster Science, 36 -4 381 -397, 2018.

[12] Kohei Arai, Sentinel 1A SAR Data Analysis for Disaster Mitigation in Kyushu, Kyushu Brunch of the Japanese Society on Remote Sensing, Special Lecture for Young Engineers on Remote Sensing, Nagasaki University, 2018.

[13] Kohei Arai, Wavelet Multi-Resolution Analysus and Its Application to Polarizatic SAR Classification, Proceeding of the SAI Computing Conference 2016.

\section{AUTHOR's PROFILE}

Kohei Arai, He received BS, MS and PhD degrees in 1972, 1974 and 1982, respectively. He was with The Institute for Industrial Science and Technology of the University of Tokyo from April 1974 to December 1978 also was with National Space Development Agency of Japan from January, 1979 to March, 1990. During from 1985 to 1987, he was with Canada Centre for Remote Sensing as a Post Doctoral Fellow of National Science and Engineering Research Council of Canada. He moved to Saga University as a Professor in Department of Information Science on April 1990. He was a councilor for the Aeronautics and Space related to the Technology Committee of the Ministry of Science and Technology during from 1998 to 2000. He was a councilor of Saga University for 2002 and 2003. He also was an executive councilor for the Remote Sensing Society of Japan for 2003 to 2005 . He is a Science Council of Japan Special Member since 2012. He is an Adjunct Professor of University of Arizona, USA since 1998. He also is Vice Chairman of the Science Commission "A" of ICSU/COSPAR since 2008 then he is now award committee member of ICSU/COSPAR. He wrote 55 books and published 620 journal papers as well as 450 conference papers. He received 66 of awards including ICSU/COSPAR Vikram Sarabhai Medal in 2016, and Science award of Ministry of Mister of Education of Japan in 2015. $\mathrm{He}$ is now Editor-in-Chief of IJACSA and IJISA. http://teagis.ip.is.sagau.ac.jp/index.html 